\title{
O ensino de química para alunos surdos e ouvintes: utilizando a experimentação como estratégia didática para o ensino de Cinética Química
}

Vilela-Ribeiro, Eveline Borges', Costa, Lorenna Silva Oliveira2; Rocha, Ana Paula Borges'; Borges, Tássia Gabriela', Vaz, Wesley Ferreira' e Benite, Anna Maria Canavarro3, Lima-Ribeiro, Matheus de Souza'.

Categoria 2. Trabalhos de investigação

\section{Resumo}

De acordo com as pesquisas realizadas, temos observado que ainda não existe uma estratégia didática padrão para ministrar uma aula de química para estudantes surdos de maneira que eles possam participar e aprender ativamente. Nesse sentido, existem problemas que são frequentemente relatados em relação ao ensino de química em espaços inclusivos. Com o intuito de buscar soluções, foi criada uma estratégia didática sobre o tópico de "Cinética Química", com a utilização de quatro experimentos, juntamente com a aula expositiva-dialogada. A estratégia didática foi avaliada a partir da resolução de questionários e criação de desenhos. Observamos que essa metodologia auxiliou na visualização dos conteúdos para todos os alunos. Dessa forma, inserimos a utilização dos aspectos visuais como facilitadora da aquisição de conhecimento científico, ajudando no processo de inclusão escolar.

\section{Palavras Chaves}

Ensino de química, surdos, experimentação e estratégia didática.

${ }^{1}$ Universidade Federal de Goiás - Regional Jataí - eveline_vilela@ufg.br

${ }^{2}$ Instituto Federal de Goiás - Campus Inhumas- lorennascosta@gmail.com

${ }^{3}$ Universidade Federal de Goiás - Regional Goiânia - anna@quimica.ufg.br 
Revista Tecné, Episteme y Didaxis: TED. Año 2014, Número Extraordinario. ISSN Impreso: 0121-3814, ISSN web: 2323-0126

Memorias, Sexto Congreso Internacional sobre Formación de Profesores de Ciencias. 08 al 10 de octubre de 2014, Bogotá

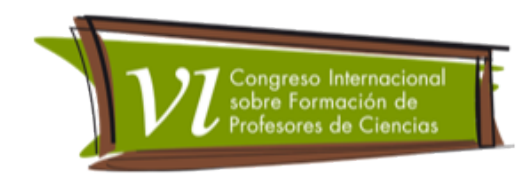

\section{Objetivo}

Elaborar e analisar uma estratégia didática sobre o tema "cinética química" para aplicação em salas de aulas com alunos surdos e ouvintes.

\section{Marco Teórico}

Atualmente, a educação inclusiva (El) é um dos temas mais abordados nas pesquisas em educação no Brasil e desenvolver sistemas educacionais inclusivos se tornou prioridade do governo brasileiro (Benite \& Ribeiro, 2012). Nesse contexto, inserimos 0 ensino de química a pessoas com deficiência auditiva, que por estarem inseridas em salas de aula com tradição predominantemente oral, enfrentam problemas no processo de ensino e aprendizagem.

Além disso, existem ainda outros problemas na enculturação científica dessas pessoas, tais como, a característica abstrata da química e sua linguagem específica, assim como a especificidade lingüística da Língua Brasileira de Sinais (Libras):

O aluno surdo não pode aprender um conteúdo transmitido em uma língua que ele não domina de fato, que restringe a sua aprendizagem a uma quantidade muito reduzida de conhecimento com qualidade (Quadros, 2006, pág. 50).

Pensando nessas situações, pesquisadores e professores passaram a elaborar diversas estratégias voltadas para a inclusão de alunos surdos em salas de aulas (Borges, 2013), considerando que é a partir das dificuldades apresentadas pelos estudantes que se deve pensar em como ensinar para alunos surdos os conteúdos que são ministrados em sala de aula. Além disso, é importante salientar que quando os estudantes surdos estão presentes em atividades não linguísticas, conseguem sentir-se mais à vontade, sendo que essas atividades podem auxiliar no raciocínio sem fornecer soluções prontas, para que possam criar suas próprias soluções e possam interagir com a turma (Lemos, Alcântara, Benite \& Benite, 2007).

Dessa forma, pensando em maneiras de se ensinar conteúdos de química para que estes sejam atraentes, primeiramente é necessário que a língua e a linguagem sejam acessíveis aos estudantes e, portanto, os conteúdos assimiláveis. Outro apontamento que devemos considerar é que conteúdos de química são 
Revista Tecné, Episteme y Didaxis: TED. Año 2014, Número Extraordinario. ISSN Impreso: 0121-3814, ISSN web: 2323-0126

Memorias, Sexto Congreso Internacional sobre Formación de Profesores de Ciencias. 08 al 10 de octubre de 2014, Bogotá

incompreendidos quando não há uma devida visualização, interferindo de maneira prejudicial no processo de aprendizagem dos estudantes ouvintes e surdos (Feltrini \& Gauche, 2007).

Assim, devido à comunicação não-efetiva em sala de aula, ou seja, sem contato e nem possibilidades de se ver o que ocorre realmente nos processos químicos, os estudantes apresentam dificuldades na compreensão de conceitos químicos. Desse modo, as aulas devem ser contextualizadas, de forma que, os estudantes possam construir seus conhecimentos a partir das experiências vivenciadas no cotidiano.

Um dos métodos pedagógicos que tem evidenciado tanto a visualização de conteúdos abstratos e a contextualização com o cotidiano dos estudantes é o desenvolvimento de atividades experimentais. Esse tipo de atividade, geralmente, privilegia a visão, direcionado para observação, com o foco em facilitar o ensinoaprendizagem do estudante surdo (Alves, Faria, Loti, Honório \& Pereira, 2011).

Assim, elaboramos e analisamos uma estratégia didática sobre "Cinética Química", sobre a qual discorremos em seguida.

\section{Metodologia}

Elaboramos uma estratégia didática sobre Cinética Química que consistiu em uma aula teórico-prática em uma turma de $2^{\circ}$ ano de ensino médio, contendo 28 alunos ouvintes e dois alunos surdos. Três aulas de cinqüenta minutos foram utilizadas. Figuras, desenhos e demonstrações em vídeo foram apresentados com a intenção de promover uma melhor visualização do conteúdo para os alunos surdos. Realizamos também quatro experimentos:

I - Concentração do alvejante na reação: Em dois béqueres adicionamos a mesma quantidade de água e corante. Em seguida, no primeiro béquer, acrescentamos $30 \mathrm{~mL}$ de alvejante e no segundo $10 \mathrm{~mL}$. O objetivo era que os alunos analisassem visualmente que o aumento da concentração no primeiro béquer faz com que a velocidade da reação seja mais rápida, em comparação ao segundo béquer.

II - A influência da temperatura em uma reação: Primeiramente adicionamos em um béquer água fria e corante, em outro béquer água quente e corante com a mesma proporção. Posteriormente adicionamos $30 \mathrm{~mL}$ de alvejante em cada 
Revista Tecné, Episteme y Didaxis: TED. Año 2014, Número Extraordinario. ISSN Impreso: 0121-3814, ISSN web: 2323-0126

Memorias, Sexto Congreso Internacional sobre Formación de Profesores de Ciencias. 08 al 10 de octubre de 2014, Bogotá

béquer. Os alunos analisaram visualmente neste experimento, como a temperatura pode influenciar na velocidade da reação.

III - Velocidade da reação com comprimidos efervescentes: Utilizamos dois comprimidos efervescentes, um triturado e outro inteiro, e adicionamos esses comprimidos em dois béqueres com mesma quantidade de água. O experimento teve o intuito de demonstrar como a superfície de contato influencia na velocidade da reação.

IV - A batata espumante: Em uma batata crua, cortada ao meio, adicionamos água oxigenada à superfície, de modo que foi possível os alunos observarem a formação de bolhas. Isso se deve em razão da decomposição da água oxigenada em água e gás oxigênio. Nessa situação, a batata crua serviu como catalisador da reação.

A fim de avaliar os estudantes, solicitamos que eles elaborassem desenhos sobre o conteúdo trabalhado. Essa opção metodológica teve relação com a possibilidade de os estudantes surdos conseguirem se expressar melhor através de representações pictográficas do que em português, já que a língua oficial para eles é a Língua Brasileira de Sinais (Libras) e não o português. Cinco representações foram utilizadas nesse trabalho, mas, de modo geral, as características observadas nelas o servem para representar os demais estudantes. Identificamos os estudantes como A1, A2, A3, A4 e A5. Os estudantes surdos são Al e A2.

\section{Resultados e Discussão}

Analisamos qualitativamente os desenhos elaborados pelos estudantes. No decorrer das aulas, observamos a recorrência de problemas que já foram descritos por outros pesquisadores (P.ex, Borges, 2013) e que nossa estratégia também não conseguiu abarcar. Por exemplo, percebemos que os estudantes surdos dependiam muito das explicações do intérprete da sala e que interagem fracamente com o professor e utilizam mais as explicações do intérprete. Além disso, os estudantes surdos interagem fracamente também com os demais estudantes da sala e mostram-se confusos sobre a quem devem observar em sala de aula, o professor ou intérprete. Entretanto, no que diz respeito à estratégia, estudantes surdos e ouvintes elaboraram suas representações de maneira semelhante, o que nos permite dizer que a estratégia didática utilizando representações visuais e experimentos é interessante para ser utilizada em salas de aulas em que hajam estudantes surdos. 
Revista Tecné, Episteme y Didaxis: TED. Año 2014, Número Extraordinario. ISSN Impreso: 0121-3814, ISSN web: 2323-0126

Memorias, Sexto Congreso Internacional sobre Formación de Profesores de Ciencias. 08 al 10 de octubre de 2014, Bogotá

De modo geral, percebemos que a principal dificuldade apresentada por todos os estudantes tem relação com o aspecto representacional do conteúdo trabalhado (Mortimer, Machado \& Romanelli, 2000). Embora aparentem entender os aspectos teóricos e fenomenológicos, têm problemas com as explicações abstratas relacionadas ao fenômeno.

Observe a Figura 1, que mostra a representação dos estudantes surdos (A1 e A2):

Figura 1: Representação de A1 (à esquerda) e A2 (à direita)

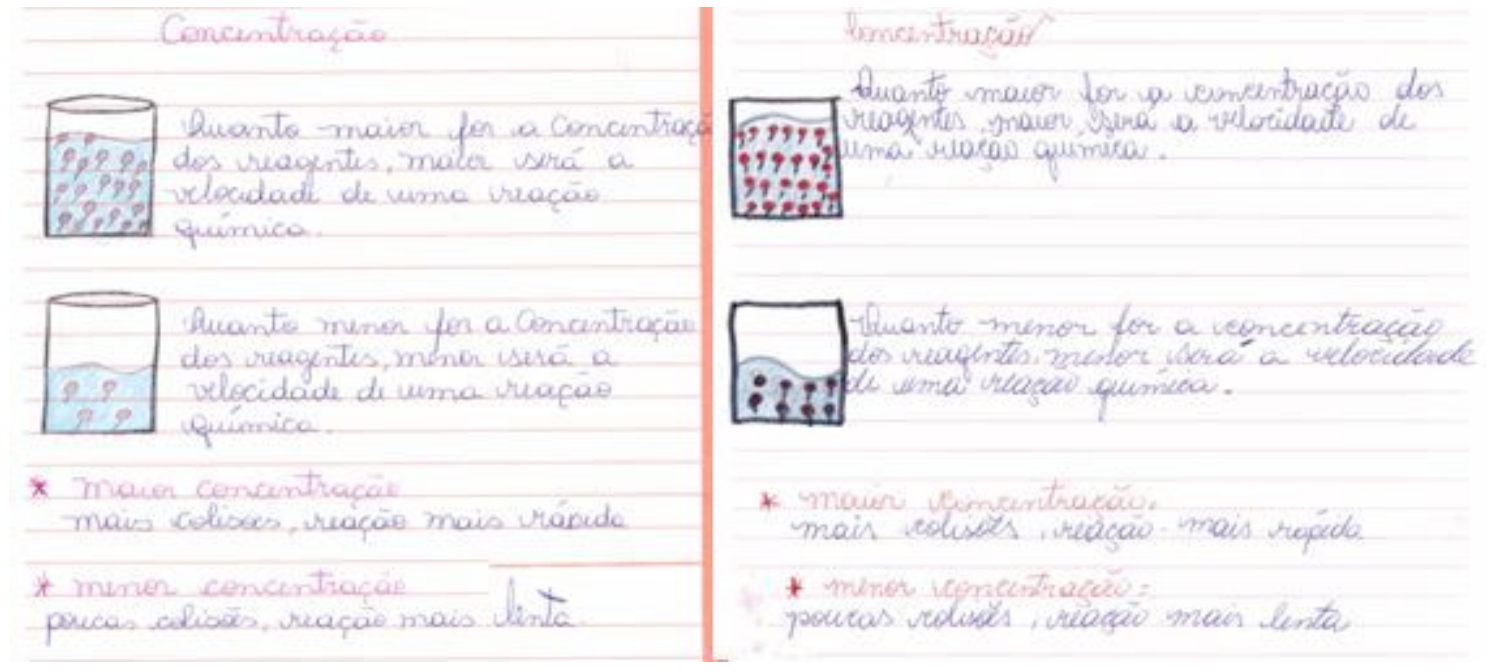

O intérprete da sala de aula explicou aos estudantes surdos a atividade que deveria ser desempenhada e eles fizeram suas próprias representações sem o auxílio da intérprete ou da professora. Entretanto, os desenhos dos estudantes abordam as mesmas temáticas e são muito parecidos. Ambos os estudantes relacionam $\mathrm{O}$ aumento da concentração com o aumento da velocidade da reação e utilizam também texto escrito para conseguirem representar o conteúdo. Até mesmo a disposição do texto e dos desenhos no papel é parecida.

Figura 2: Representação de A3.

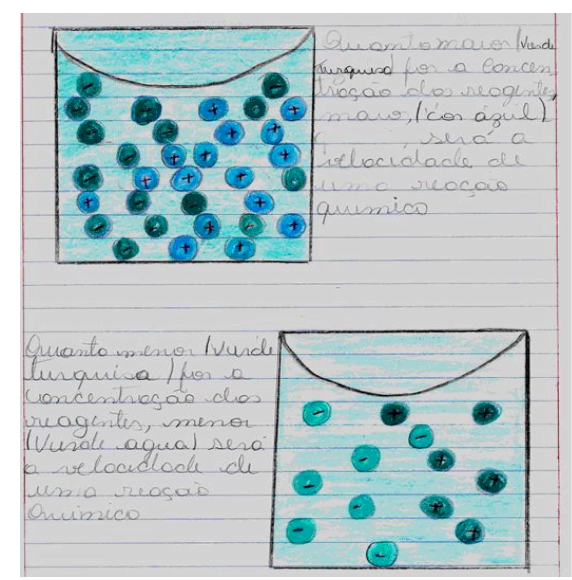


Revista Tecné, Episteme y Didaxis: TED. Año 2014, Número Extraordinario. ISSN Impreso: 0121-3814, ISSN web: 2323-0126

Memorias, Sexto Congreso Internacional sobre Formación de Profesores de Ciencias. 08 al 10 de octubre de 2014, Bogotá

Teoricamente, o aumento da concentração dos reagentes faz com que se tenha uma maior quantidade de partículas ou moléculas, confinadas num mesmo espaço. Isso aumenta a quantidade de choques entre elas e aumenta também a probabilidade de ocorrerem colisões eficazes que resultem na ocorrência da reação. O resultado é que a reação ocorre com maior rapidez, portanto, quanto maior for à concentração dos reagentes, maior será a velocidade de uma reação química. Essa é a explicação microscópica para o aumento da velocidade da reação quando há aumento na concentração dos reagentes.

De acordo com a figura de A3, observamos que o aluno utilizou sinais negativos para o aumento da concentração, e sinais positivos para o aumento da velocidade das reações. Na segunda parte, ele utilizou novamente sinais simbolizando a diminuição da concentração, como conseqüência da diminuição da velocidade da reação. Embora o sentido de sua explicação esteja correto, o aspecto representacional da química foi negligenciado.

Observe agora as Figuras 3 e 4.

Figura 3: Representação A4.

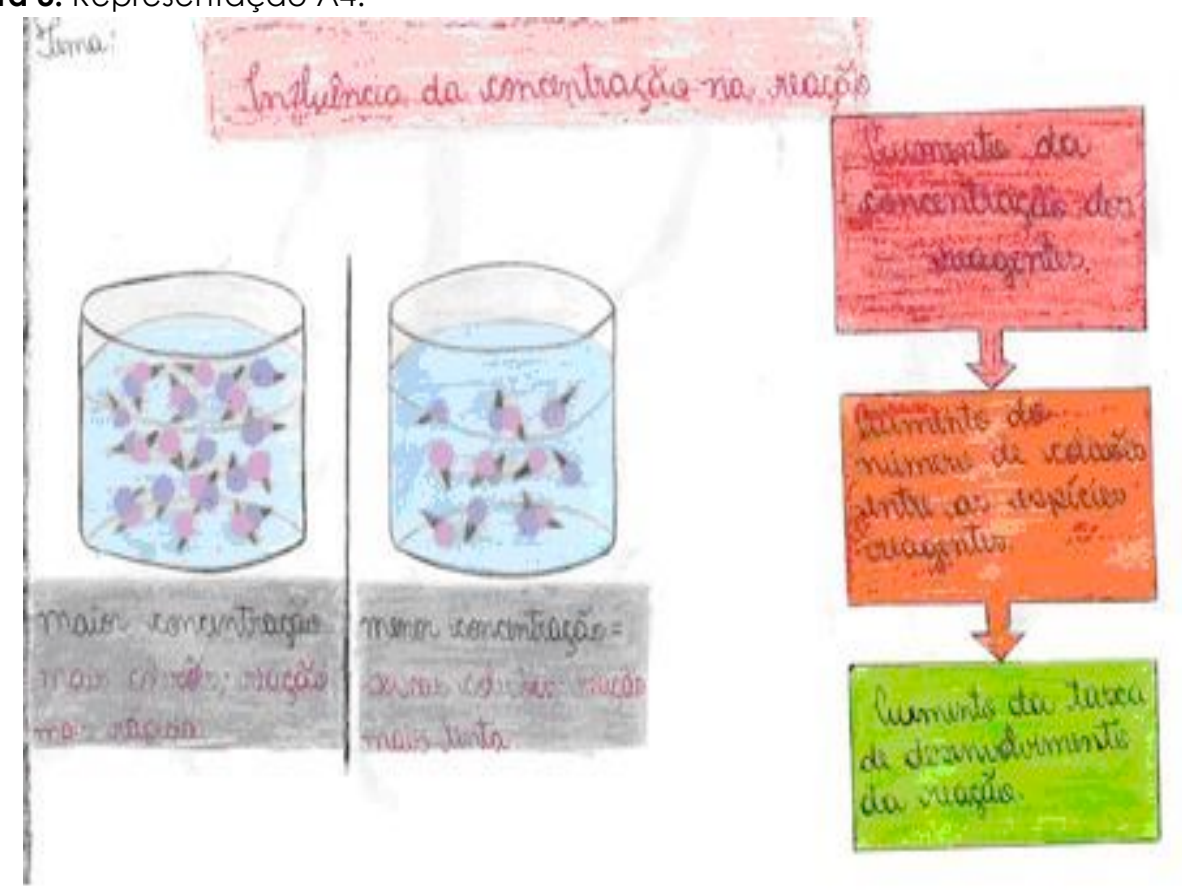

Na figura 3 podemos perceber a representação de A4 para quais fatores podem influenciar a velocidade da reação. O aluno representa as moléculas se agitando 
Revista Tecné, Episteme y Didaxis: TED. Año 2014, Número Extraordinario. ISSN Impreso: 0121-3814, ISSN web: 2323-0126

Memorias, Sexto Congreso Internacional sobre Formación de Profesores de Ciencias. 08 al 10 de octubre de 2014, Bogotá

através de "setas". De um lado existe maior quantidade de moléculas e do outro menor quantidade, evidenciado que quanto maior a concentração dos reagentes, maior será a velocidade da reação e que deve ocorrer uma colisão entre as moléculas para que ocorra essa reação. Novamente, embora A4 tenha mostrado entendimento quanto ao conteúdo, ele não consegue fazer uma representação do tema sem utilizar palavras, frases e explicações. Ele não consegue também demonstrar os choques entre as moléculas e como isso redunda em um aumento na velocidade da reação.

A5 mostrou como a concentração pode influenciar a velocidade da reação, através do esboço de um béquer inicialmente com alguns reagentes, após alguns segundos ocorreu a reação mais rápida no primeiro béquer (Figura 4). Entendemos que o intuito foi mostrar que quanto maior a concentração dos reagentes, maior será a velocidade da reação. O estudante fez relação com um dos experimentos utilizados durante a aula (Experimento I), mas também não abordou os aspectos microscópicos e simbólicos envolvidos.

Figura 4: Representação do A5.

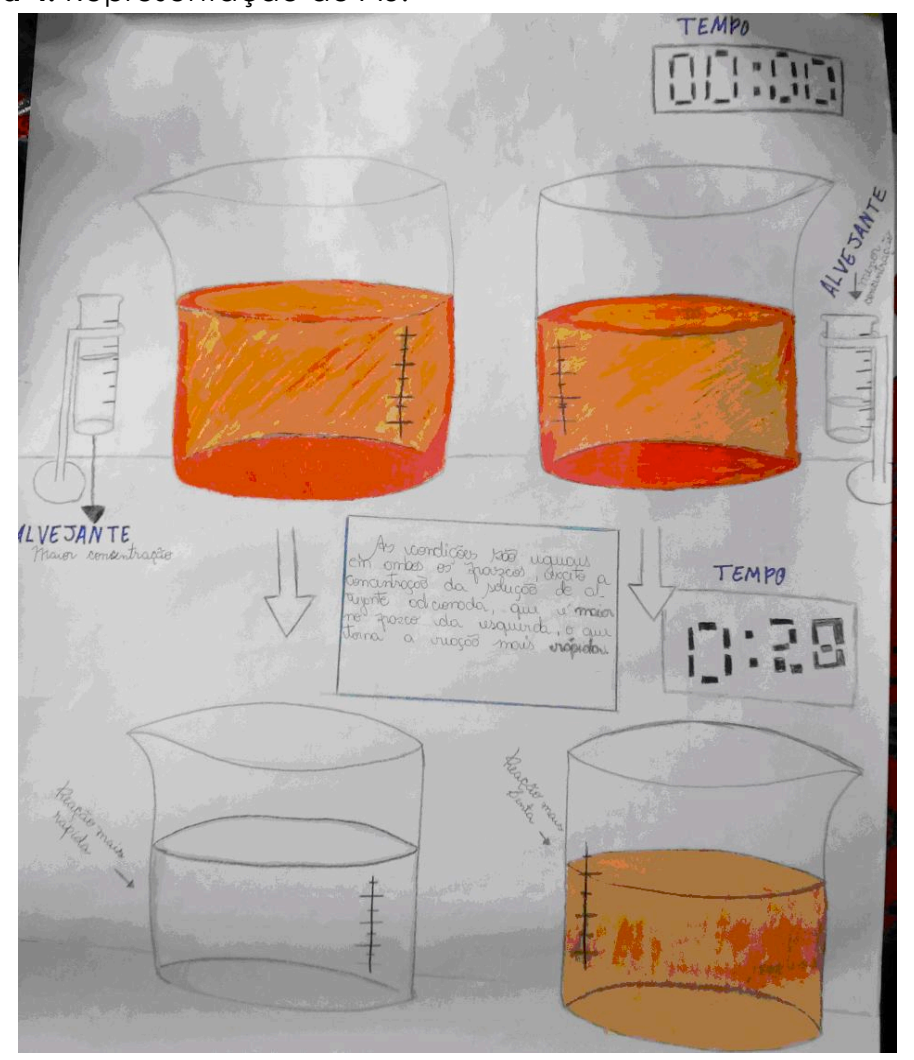


Revista Tecné, Episteme y Didaxis: TED. Año 2014, Número Extraordinario. ISSN Impreso: 0121-3814, ISSN web: 2323-0126

Memorias, Sexto Congreso Internacional sobre Formación de Profesores de Ciencias. 08 al 10 de octubre de 2014, Bogotá

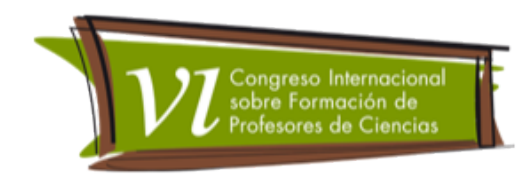

\section{Conclusões}

As atividades práticas como também os desenhos foram ferramentas auxiliares no desenvolvimento da observação, elaboração e significação dos conceitos relacionados ao tema Cinética Química. Assim, conseguimos perceber que embora a estratégia didática tenha enfocado os aspectos representacionais, teóricos e fenomenológicos da cinética química, os estudantes não conseguiram interrelacionar todos esses aspectos. Quanto à tentativa de a estratégia didática ser inclusiva, acreditamos que o fato de os estudantes surdos mostrarem representações similares aos outros estudantes, mostra que a estratégia didática conseguiu, pelo menos minimamente, integrá-los ao processo de ensino.

\section{Agradecimentos}

À Fundação de Amparo à Pesquisa do Estado de Goiás (Fapeg) pelo apoio financeiro a MSL-R para participação do evento.

\section{Referências Bibliográficas}

Alves, K. G., Faria, P. P., Loti, S., Daher, V.,Honorio, H. \& Pereira, V. (2011). O Ensino de Química para Surdos: a relevância dos aspectos visuais. In: Atas do V Encontro Regional Sul de Ensino de Biologia (Erebio-Sul), pág.18-21 Set. 2011.

Borges, F. A. A (2013). Educação Inclusiva para Surdos: uma análise do saber matemático intermediado pelo intérprete de Libras. Tese de Doutorado. Universidade Estadual de Maringá, Maringá, Brasil.

Feltrini, G. M. \& Gauche, R. (2007). Ensino de Ciências a Estudantes surdos: pressupostos e desafios. In: Atas do VI Encontro Nacional de Pesquisa em Educação em Ciências. pág. 26-30 nov. 2007.

Lemos, L. N., Alcântara, M. M., Benite, C. R. M. \& Benite, A. M. C. (2007). O Ensino de Química e a Aprendizagem de Alunos Surdos: uma interação mediada pela visão. Universidade Federal de Goiás. In: Atas do VI Encontro Nacional de Pesquisa em Educação em Ciências. pág. 26-30 nov. 2007.

Mortimer, E.F.; Machado, A.H. \& Romanelli, L.I. (2000). A proposta curricular de química no estado de Minas Gerais: fundamentos e pressupostos. Química Nova, pág. 23(2). 
Revista Tecné, Episteme y Didaxis: TED. Año 2014, Número Extraordinario. ISSN Impreso: 0121-3814, ISSN web: 2323-0126

Memorias, Sexto Congreso Internacional sobre Formación de Profesores de Ciencias. 08 al 10 de octubre de 2014, Bogotá

Quadros, R. (2006) Políticas linguísticas e educação de surdos em Santa Catarina: espaço de negociações. Caderno Cedes, pág. 26(69).

Vilela-Ribeiro, E. B. Benite \& A. M. C. (2012). Temas em Educação Inclusiva: fundamentos para a sala de aula de Ciências. Madrid: Editorial Acadêmica Espanola. 